\title{
Vitamin C supplementation of the maternal diet reduces the rate of malformation in the offspring of diabetic rats
}

\author{
C.M.Simán, U.J. Eriksson \\ Department of Medical Cell Biology, Uppsala University, Uppsala, Sweden
}

\begin{abstract}
Summary An excess of reactive oxygen species (ROS) has been associated with the increased rate of congenital malformations in experimental diabetic pregnancy. Previous in vitro and in vivo studies show that antioxidants can protect the embryonic development in a diabetic environment. In the present investigation we examined the antiteratogenic capacity of vitamin $\mathrm{C}$, an antioxidative agent not previously evaluated as a dietary supplement in diabetic pregnancy. Normal and streptozotocin diabetic rats were either fed a standard diet or a diet enriched with $0.9,1.8$ or $4 \%$ sodium ascorbate throughout pregnancy. On gestational day 20, the litters of normal and diabetic rats without vitamin $\mathrm{C}$ supplement contained 9 and $12 \%$ early resorptions, 2 and $17 \%$ late resorptions and 1 and $27 \%$ malformations, respectively. Vitamin C treatment reduced the rates of late resorptions and malformations in the diabetic groups in proportion to the dose administered. Thus, in the diabetic group with $4 \%$ ascorbate treatment we found unchanged
\end{abstract}

numbers of early resorptions, but only $7 \%$ late resorptions ( $p<0.05$ vs untreated diabetic pregnancy) and $8 \%$ malformations $(p<0.05$ vs untreated diabetic pregnancy). Maternal diabetes did not alter tissue levels of ascorbic acid in the fetuses at term, whereas vitamin $\mathrm{C}$ treatment caused accumulation of ascorbic acid in the placenta, maternal and fetal liver. Vitamin $C$ supplementation yielded increased $\alpha$-tocopherol concentration in the placenta and caused a reduction of the high concentrations of thiobarbituric acid reactive substances (TBARS) in serum of pregnant diabetic rats. Vitamin $\mathrm{C}$ treatment reduces the rates of congenital malformations and late resorptions, thereby supporting that ROS are involved in the embryonic dysmorphogenesis of diabetic pregnancy. [Diabetologia (1997) 40: 1416-1424]

Keywords Diabetic pregnancy, streptozotocin, rat, embryo, fetus, congenital malformation, vitamin C, antioxidant therapy, TBARS, oxidative stress.
Received: 15 April 1997 and in revised form: 12 August 1997

Corresponding author: C.M.Simán, Department of Medical Cell Biology, Uppsala University, Biomedicum, P. O. Box 571, S-751 23 Uppsala, Sweden

Abbreviations: BHT, Butylated hydroxytoluene; 3-DG, 3-deoxyglucosone; GLUT 1, glucose transporter 1; GSH, glutathione, reduced; IDDM, insulin-dependent diabetes mellitus; MD, manifestly diabetic rat; MDC $0.9 \%$, MD with $0.9 \%$ ascorbate treatment; MDC $1.8 \%$, MD with $1.8 \%$ ascorbate treatment; MDC $4 \%$, MD with $4 \%$ ascorbate treatment; $\mathrm{N}$, normal, non-diabetic rat; NC $1.8 \%, \mathrm{~N}$ with $1.8 \%$ ascorbate treatment; $\mathrm{NC} 4 \%$, $\mathrm{N}$ with $4 \%$ ascorbate treatment; ROS, reactive oxygen species; STZ, streptozotocin; TBARS, thiobarbituric acid reactive substances.
Although improved metabolic control of maternal diabetes has reduced the rate of complications during pregnancy, the incidence of congenital malformations is still increased in children of insulin-dependent-diabetic (IDDM) mothers [1-4]. The mechanisms by which maternal diabetes disrupts embryonic development are not completely understood, but the risk of fetal malformation is strongly correlated to the maternal glucose concentration [2-4]. Maternal levels of triglycerides, $\beta$-hydroxybutyrate and branched chain amino acids are also of importance for the occurrence of fetal dysmorphogenesis [5]. In the embryo, disturbed metabolism of sorbitol, inositol, arachidonic acid and prostaglandins has been demonstrated in experimental diabetic pregnancy and 
should have teratologic significance [6]. In addition, excess embryonic reactive oxygen species (ROS) has been implicated in the aetiology of diabetes-induced congenital malformations [6].

In diabetic pregnancy, experimental studies have indicated increased production of ROS $[7,8]$ and reduced concentrations of $\alpha$-tocopherol [9] in embryonic tissues. We and others have shown that the disturbed development of embryos in a diabetic milieu can be normalised by treatment with different antioxidants both in vitro and in vivo [7, 9-19]. These compounds include $\mathrm{N}$-acetylcysteine, reduced glutathione (GSH) ester, superoxide dismutase, catalase, glutathione peroxidase, butylated hydroxytoluene, lipoic acid and vitamin E - a variety of substances with essentially only antioxidative capacity in common. Notably, ascorbate (vitamin C) has not been previously studied in this context.

Ascorbic acid concentrations in tissues and plasma are reported to be decreased in both animals and humans with diabetes [20-23]. Vitamin $\mathrm{C}$ acts as an antioxidant to protect cellular components from ROS induced damage $[24,25]$. In addition, ascorbic acid plays an important role in many biochemical processes, such as collagen synthesis [26], cholesterol synthesis [27, 28] and iron absorption [29]. Ascorbic acid is synthesized from D-glucose in most species, with the exception of primates and guinea pigs [30]. Transport of vitamin $\mathrm{C}$ through biological membranes is facilitated by glucose transporters, especially GLUT1 [31-33], and hence, hyperglycaemia has been shown to reduce placental transport of ascorbic acid to the fetus $[34,35]$. Ascorbic acid is a water soluble antioxidant, and has the potential to scavenge the superoxide and hydroperoxyl radicals, which are physiological ROS [36]. In addition, ascorbic acid may function as a chain-breaking antioxidant in the lipid phase by an interaction with lipid soluble antioxidants such as vitamin $\mathrm{E}$ and coenzyme $\mathrm{Q}[36$, 37]. Ascorbate is the primary antioxidant to be consumed in plasma exposed to oxidative stress [38, 39], and ascorbate is regarded as the most important scavenger of oxygen radicals in the aqueous phase [25]. However, in the presence of transition metals, ascorbate auto-oxidizes in vitro, and superoxide formation occurs [40]. The significance of the prooxidant activity in vivo is unclear [41], mainly due to low concentrations of free metal ions under physiological conditions [42] and high concentrations of urate in plasma which inhibits ascorbate auto-oxidation [43].

By testing the hypothesis that ROS excess is involved in the aetiology of diabetes-induced dysmorphogenesis, we investigated whether supplementation of the maternal diet with ascorbate may restore or normalize the disturbed embryonic development in diabetic pregnancy. Ascorbate has been used previously in the treatment of several diabetic complications [44-47], but has not yet been evaluated in the field of diabetic embryopathy.

\section{Materials and methods}

Animals. A local malformation-prone strain of Sprague-Dawley rats was used in the experiments [48]. The rats were subjected to a 12/12 h light/dark cycle and had free access to tap water and laboratory chow (see below). Some of the virgin female rats were made manifestly diabetic (MD) by a single intravenous injection of streptozotocin (STZ $40 \mathrm{mg} / \mathrm{kg}$, a gift from Pharmacia \& Upjohn, Kalamazoo, Mich., USA) 12 weeks before mating with non-diabetic males of the same strain. Untreated virgin females served as normal, non-diabetic controls (N). Manifest diabetes was defined as a serum glucose concentration exceeding $20 \mathrm{mmol} / \mathrm{l}$ (Glucose Analyser 2; Beckman Instruments Inc., Fullerton, Calif., USA) 1 week after the STZ injection. All experimental procedures involving animals were approved by the animal ethics committee of the Medical Faculty of Uppsala University.

Treatment with vitamin $C$. The rats were given powdered rat chow supplemented with sodium ascorbate (Merck, Darmstadt, Germany) at the concentrations $0.9,1.8$ or $4 \%$ (wt/wt, cf. Fig. 1). The food was prepared by blending ascorbate into ground rat chow (R36; Lactamin AB, Stockholm, Sweden).

Induction and course of pregnancy. One week after the STZ injection the rats were mated overnight and the morning that sperm were found in the vaginal smear was designated gestational day 0 . On gestational day 20 the pregnant rats were anaesthetised with ether and then blood was collected from the abdominal aorta (Fig.1). Serum was prepared by centrifugation and immediately frozen in liquid nitrogen. The maternal livers were dissected, weighed, and stored at $-135^{\circ} \mathrm{C}$ after rapid freezing in liquid nitrogen. The uterine horns were cut open and carefully inspected to reveal all implantations, both viable and non-viable, regardless of size. Viable fetuses and their placentae were weighed and the fetuses were examined for gross malformations, as previously outlined [49]. Briefly, viable fetuses were denoted malformed when they showed facial abnormalities (mainly micrognathia), absence of tail, omphalocele, cranial anomalies, or other gross malformation. Inspection of the resorbed sites yielded a cut-off diameter of $4 \mathrm{~mm}$, which divided the resorptions into those with no identifiable fetal tissues (diameter $<4 \mathrm{~mm}$, essentially only a lump of non-maternal tissue, these were denoted "early resorptions"), and those with one or more identifiable tissues (diameter $>4 \mathrm{~mm}$, placenta and often embryo-fetus identifiable, denoted "late resorptions"). The fetal liver, brain and heart were randomly collected from four viable fetuses in each litter. If malformed fetuses were present in a litter, 1-2 of them were used for organ collection.

Chemical analysis. Maternal liver, placenta and fetal tissues of $\mathrm{N}, \mathrm{NC} 4 \%$, MD and MDC $4 \%$ groups were homogenized in double distilled water at a concentration of $200 \mathrm{~g} / \mathrm{l}$. These homogenates and maternal serum were used for determination of lipid peroxidation (thiobarbituric acid reactive substances, TBARS), ascorbic acid and $\alpha$-tocopherol. The chemicals used in the study were purchased from Merck.

Analysis of ascorbic acid. Quantification of ascorbic acid was performed according to Jagota and Dani [50]. Initially $200 \mu \mathrm{l}$ of serum, tissue homogenate or standard preparations of ascorbic 
Table 1. Maternal body weight on gestational day 0 , day 20 and the weight gain during pregnancy, maternal liver weight and serum glucose by the interruption of pregnancy at gestational day 20

\begin{tabular}{lrllllc}
\hline Group & $n$ & Weight day 0 $(\mathrm{g})$ & Weight day 20 $(\mathrm{g})$ & Weight gain $(\mathrm{g})$ & Liver weight $(\mathrm{g})$ & Glucose $(\mathrm{mmol} / \mathrm{l})$ \\
\hline $\mathrm{N}$ & 10 & $259 \pm 5$ & $349 \pm 11$ & $90 \pm 8$ & $10.2 \pm 0.3$ & $5.7 \pm 0.2$ \\
NC 1.8\% & 4 & $262 \pm 7$ & $250 \pm 6$ & $88 \pm 8$ & $10.5 \pm 0.8$ & $5.7 \pm 0.2$ \\
NC 4\% & 6 & $260 \pm 5$ & $363 \pm 5$ & $103 \pm 7$ & $10.6 \pm 0.5$ & $6.6 \pm 0.2$ \\
MD & 15 & $255 \pm 4$ & $294 \pm 6^{\mathrm{c}}$ & $42 \pm 4^{\mathrm{c}}$ & $13.1 \pm 0.9^{\mathrm{b}}$ & $35.3 \pm 1.0^{\mathrm{c}}$ \\
MDC 0.9\% & 6 & $258 \pm 7$ & $297 \pm 13^{\mathrm{c}}$ & $39 \pm 10^{\mathrm{c}}$ & $13.3 \pm 0.8^{\mathrm{b}}$ & $30.5 \pm 1.3^{\mathrm{c}, \mathrm{e}}$ \\
MDC 1.8\% & 14 & $247 \pm 3^{\mathrm{a}}$ & $300 \pm 9^{\mathrm{c}}$ & $54 \pm 8^{\mathrm{c}}$ & $13.2 \pm 0.5^{\mathrm{b}}$ & $34.6 \pm 0.3^{\mathrm{c}}$ \\
MDC 4 \% & 11 & $254 \pm 5$ & $302 \pm 9^{\mathrm{c}}$ & $47 \pm 10^{\mathrm{c}}$ & $12.5 \pm 0.4^{\mathrm{b}}$ & $38.5 \pm 1.2^{\mathrm{c}, \mathrm{d}}$
\end{tabular}

Normal and diabetic rats with standard diet (N and $\mathrm{MD})$ or with $0.9 \%$ (MDC $0.9 \%$ ), $1.8 \%$ (NC $1.8 \%$ and MDC $1.8 \%$ ) or $4 \%$ (NC $4 \%$ and MDC $4 \%$ ) ascorbate added to the diet. Data are presented as mean \pm SEM. $n=$ number of observations
Statistical analysis with ANOVA: ${ }^{\mathrm{a}} p<0.05 \mathrm{vs} \mathrm{N} ;{ }^{\mathrm{b}} p<0.01 \mathrm{vs}$ $\mathrm{N} ;{ }^{\mathrm{c}} p<0.001$ vs $\mathrm{N} ;{ }^{\mathrm{d}} p<0.05$ vs MD; ${ }^{\mathrm{e}} p<0.01$ vs MD acid was precipitated with $800 \mu \mathrm{l}$ trichloroacetic acid on ice for $5 \mathrm{~min}$ and centrifuged at $3000 \mathrm{rev} / \mathrm{min}$. Thereafter, $500 \mu \mathrm{l}$ of the supernatant was diluted to $2 \mathrm{ml}$ with double distilled water, and $200 \mu \mathrm{l}$ of Folin-Ciocalteus reagent, diluted in double distilled water (1:9), was added. After 10 min the absorbance of the samples was measured at $760 \mathrm{~nm}$ with a Beckman DU-65 Spectrophotometer (Beckman Instruments Inc.).

Analysis of $\alpha$-tocopherol. To estimate the content of $\alpha$-tocopherol, $500 \mu \mathrm{l}$ of the tissue homogenate or serum in water was initially diluted with an aliquot of $500 \mu \mathrm{l}$ methanol. The sample was manually shaken for 3 min with $2 \mathrm{ml}$ of hexane in a Teflon capped glass tube and then centrifuged. For fetal samples, the hexane phase was concentrated 10 times by drying under a stream of nitrogen and dilution in $200 \mu$ l of hexane. Subsequently, $100 \mu \mathrm{l}$ of the hexane phase was analysed by normal phase HPLC by injection into a $5 \mu \mathrm{m}$ Spherisorb amino column $(4.6 \times 250 \mathrm{~mm}$, Phase Separation Ltd, Deeside, UK $)$ at a flow rate of $1 \mathrm{ml} / \mathrm{min}$. The eluent was isocratic isooctane/tertbutyl-methyl-ether/methanol (75/25/0.5). The effluent was monitored with a Shimadzu RF-10 A Fluorometer (Shimadzu Corporation, Kyoto, Japan) at excitation wavelength $295 \mathrm{~nm}$ and emission wavelength $327 \mathrm{~nm}$. $\alpha$-Tocopherol eluted at approximately $4.5 \mathrm{~min}$.

Analysis of TBARS. TBARS was determined by a modified version of the method described by Mihara et al. [51]. Initially, $200 \mu \mathrm{l}$ of the tissue homogenate or serum was boiled with $750 \mu \mathrm{l}$ phosphoric acid $(0.19 \mathrm{~mol} / \mathrm{l}), 250 \mu \mathrm{l}$ thiobarbituric acid $(42 \mathrm{mmol} / \mathrm{l})$ and $300 \mu \mathrm{l}$ double distilled water for $60 \mathrm{~min}$. After boiling the samples were precipitated with an aliquot of methanol/NaOH (91/9, $1 \mathrm{~mol} / \mathrm{l} \mathrm{NaOH})$ and centrifuged for $5 \mathrm{~min}$. The supernatant was measured fluorometrically at excitation wavelength $532 \mathrm{~nm}$ and emission wavelength $553 \mathrm{~nm}$ (Perkin Elmer LS 5B luminescence spectrophotometer; Perkin Elmer Ltd, Beaconsfield, Buckinghamshire, UK). Standards were prepared from malonyldialdehydbis(dietylacetal) and were treated identically as the tissue homogenates.

Statistical analysis. Mean \pm SEM for the treatment groups was calculated from litter means. Significant differences between and within groups were estimated from litter means by analysis of variance (ANOVA) with the applied test of Fishers Protected Least Significant Difference ad modum Winer [52], or the Mann-Whitney U-test [53]. Significance levels are given in each table legend. A numerical difference between means which yielded a $p$-value in the range of 0.05 to 0.1 was denoted "tendency" in the text. The statistical analyses were performed using the program StatView (version 4.02) for Macintosh.

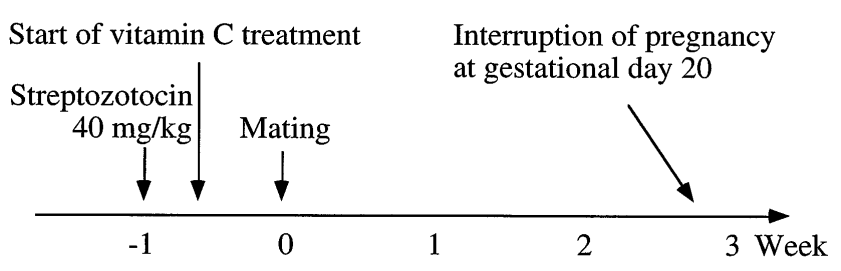

Fig. 1. Experimental design

\section{Results}

Maternal status. On the day of conception, the mean weight of the rats in the diabetic groups tended to be smaller than the mean weight of those in the normal groups (Table 1). During pregnancy the diabetic groups gained less weight than the normal groups, regardless of diet. The ascorbate addition to the diet did not appear to have any negative effects on animal health, food consumption, or weight gain. The liver weight was increased in the diabetic groups compared to the normal groups. Again, this was not affected by ascorbate treatment. The serum glucose concentration of the STZ-diabetic rats was elevated about six times compared to that of the normal rats. Ascorbate treatment did not exert any consistent effect on serum glucose concentrations (Table 1).

Outcome of pregnancy. The mean number of implantations per litter were similar in all groups regardless of diabetes and ascorbate treatment (Table 2). The total numbers of resorptions were increased in all the diabetic groups, and no consistent effect of ascorbate treatment could be identified (Table 2). Comparing early and late resorptions, however, revealed that the early resorption rate was similar in the normal and diabetic groups, whereas the rate of late resorptions was increased in the MD group (Table 3). Ascorbate treatment did not affect early resorptions but decreased the frequency of late resorptions in the diabetic groups (Table 3). The malformation rate was increased in the diabetic groups compared to the normal groups, as expected, but was decreased 
Table 2. Outcome of pregnancy on gestational day 20

\begin{tabular}{|c|c|c|c|c|c|c|c|c|c|}
\hline & $\begin{array}{l}\text { Litters } \\
\text { No. }\end{array}$ & $\begin{array}{l}\text { Impl } \\
\text { No. }\end{array}$ & $\begin{array}{l}\text { Res } \\
\text { No. }\end{array}$ & $\begin{array}{l}\text { Malf } \\
\text { No. }\end{array}$ & $\begin{array}{l}\text { Mean } \\
\text { Impl/litter }\end{array}$ & $\begin{array}{l}\text { Mean } \\
\text { Res/litter }\end{array}$ & $\begin{array}{l}\text { Mean } \\
\text { Malf/litter }\end{array}$ & $\begin{array}{l}\text { Res \%/ } \\
\text { litter }\end{array}$ & $\begin{array}{l}\text { Malf \%/ } \\
\text { litter }\end{array}$ \\
\hline $\mathrm{N}$ & 10 & 109 & 12 & 1 & $10.9 \pm 0.9$ & $1.2 \pm 0.7$ & $0.1 \pm 0.1$ & $11.2 \pm 6.7$ & $1.2 \pm 1.2$ \\
\hline NC $1.8 \%$ & 4 & 47 & 7 & 0 & $11.7 \pm 0.6$ & $1.7 \pm 1.1$ & 0 & $16.7 \pm 11.3$ & 0 \\
\hline $\mathrm{MD}$ & 15 & 164 & 53 & 26 & $10.9 \pm 0.8$ & $3.5 \pm 0.8^{\mathrm{a}}$ & $1.7 \pm 0.3^{c}$ & $29.3 \pm 5.6^{\mathrm{b}}$ & $27.2 \pm 6.6^{c}$ \\
\hline MDC $0.9 \%$ & 6 & 66 & 17 & 8 & $11.0 \pm 1.0$ & $2.8 \pm 0.9$ & $1.3 \pm 0.3^{\mathrm{b}}$ & $25.1 \pm 7.2$ & $18.2 \pm 5.6^{\mathrm{b}}$ \\
\hline MDC $1.8 \%$ & 14 & 144 & 22 & 14 & $10.3 \pm 0.9$ & $1.6 \pm 0.4^{\mathrm{d}}$ & $1.0 \pm 0.3^{\mathrm{b}}$ & $17.9 \pm 5.0$ & $12.8 \pm 3.8^{\mathrm{a}}$ \\
\hline
\end{tabular}

Normal and diabetic rats with standard diet (N and MD) or with $0.9 \%$ (MDC $0.9 \%$ ), $1.8 \%$ (NC $1.8 \%$ and MDC $1.8 \%$ ) or $4 \%$ (NC $4 \%$ and MDC $4 \%$ ) ascorbate added to the diet. Implantations, resorptions and malformations are given as absolute number, mean number per litter and mean proportion per litter (\%), the two later categories as mean \pm SEM.

Statistical analysis with Mann-Whitney U-test: ${ }^{a} p<0.05$ vs N; ${ }^{\mathrm{b}} p<0.01$ vs $\mathrm{N} ;{ }^{\mathrm{c}} p<0.001$ vs $\mathrm{N} ;{ }^{\mathrm{d}} p<0.05$ vs MD

Table 3. Early and late resorptions on gestational day 20

\begin{tabular}{|c|c|c|c|c|c|c|c|}
\hline & $\begin{array}{l}\text { Impl } \\
\text { No. }\end{array}$ & $\begin{array}{l}\text { Early res } \\
\text { No. }\end{array}$ & $\begin{array}{l}\text { Late res } \\
\text { No. }\end{array}$ & $\begin{array}{l}\text { Early res/ } \\
\text { litter }\end{array}$ & $\begin{array}{l}\text { Late res/ } \\
\text { litter }\end{array}$ & $\begin{array}{l}\% \text { Early } \\
\text { res/litter }\end{array}$ & $\begin{array}{l}\% \text { Late } \\
\text { res/litter }\end{array}$ \\
\hline $\mathrm{N}$ & 109 & 10 & 2 & $1.0 \pm 0.5$ & $0.2 \pm 0.2$ & $9.2 \pm 4.7$ & $2.0 \pm 2.0$ \\
\hline NC $1.8 \%$ & 47 & 5 & 2 & $1.3 \pm 0.6$ & $0.5 \pm 0.5$ & $11.7 \pm 6.4$ & $5.0 \pm 5.0$ \\
\hline MD & 164 & 22 & 31 & $1.5 \pm 0.5$ & $2.1 \pm 0.4^{\mathrm{c}}$ & $11.7 \pm 3.9$ & $17.5 \pm 2.8^{\mathrm{b}}$ \\
\hline MDC $0.9 \%$ & 66 & 9 & 8 & $1.5 \pm 0.6$ & $1.3 \pm 0.6^{\mathrm{a}}$ & $12.5 \pm 4.9$ & $12.6 \pm 4.9^{\mathrm{a}}$ \\
\hline MDC $1.8 \%$ & 144 & 13 & 9 & $0.9 \pm 0.2$ & $0.6 \pm 0.3^{\mathrm{e}}$ & $12.2 \pm 4.6$ & $5.7 \pm 2.8^{\mathrm{e}}$ \\
\hline
\end{tabular}

Normal and diabetic rats with standard diet (N and MD) or with $0.9 \%$ (MDC $0.9 \%$ ), $1.8 \%$ (NC $1.8 \%$ and MDC $1.8 \%$ ) or $4 \%$ (NC $4 \%$ and MDC $4 \%$ ) ascorbate added to the diet. Number of implantations, early and late resorptions are given

Table 4. Fetal and placental weight on gestational day 20

\begin{tabular}{lrll}
\hline & $n$ & $\begin{array}{l}\text { Fetal weight } \\
(\mathrm{g})\end{array}$ & $\begin{array}{l}\text { Placental weight } \\
(\mathrm{g})\end{array}$ \\
\hline $\mathrm{N}$ & 10 & $3.87 \pm 0.05$ & $0.56 \pm 0.03$ \\
$\mathrm{NC} 1.8 \%$ & 4 & $3.65 \pm 0.05$ & $0.50 \pm 0.01$ \\
$\mathrm{NC} 4 \%$ & 7 & $3.74 \pm 0.07$ & $0.60 \pm 0.04$ \\
$\mathrm{MD}$ & 15 & $2.62 \pm 0.09^{\mathrm{c}}$ & $0.66 \pm 0.01^{\mathrm{b}}$ \\
MDC $0.9 \%$ & 5 & $2.81 \pm 0.13^{\mathrm{c}}$ & $0.63 \pm 0.03$ \\
MDC $1.8 \%$ & 14 & $2.79 \pm 0.10^{\mathrm{c}}$ & $0.63 \pm 0.03$ \\
MDC $4 \%$ & 11 & $2.72 \pm 0.07^{\mathrm{c}}$ & $0.61 \pm 0.02$ \\
\hline
\end{tabular}

Normal and diabetic rats with standard diet (N and MD) or with $0.9 \%$ (MDC $0.9 \%$ ), $1.8 \%$ (NC $1.8 \%$ and MDC $1.8 \%$ ) or $4 \%$ (NC $4 \%$ and MDC $4 \%$ ) ascorbate added to the diet. Data are presented as mean \pm SEM. $n=$ number of observations Statistical analysis with ANOVA: ${ }^{\mathrm{b}} p<0.01 \mathrm{vs} \mathrm{N} ;{ }^{\mathrm{c}} p<0.001$ vs N

by ascorbate treatment. The decrease of the malformation rate was proportional to the increase in ascorbate dose in the diet. Micrognathia accounted for $79 \%$ of all malformations, although it was never found in any of the normal groups, as previously observed [48]. Cranial skeletal anomalies (micrognathia, exencephaly, short nose, distorted mid face with protruding forehead) accounted for $87 \%$ of the malformations, whereas absence of tail $(11 \%)$, and omphalocele $(2 \%)$ were much less common. Ascorbate treatment prevented micrognathia in a dose-dependent manner (data not shown), whereas as absolute number, mean number per litter and mean proportion per litter (\%)

Statistical analysis with Mann-Whitney U-test: ${ }^{\mathrm{a}} p<0.05 \mathrm{vs} \mathrm{N}$; ${ }^{\mathrm{b}} p<0.01$ vs N; ${ }^{\mathrm{c}} p<0.001$ vs N; ${ }^{\mathrm{d}} p<0.05$ vs $\mathrm{MD} ;{ }^{\mathrm{e}} p<0.01$ vs MD

the other anomalies were too few to allow a statistical analysis. Altogether, the data show that ascorbate treatment decreases the rates of malformations and late resorptions, but not early resorptions (Fig. 2).

Fetal and placental weights. Fetuses from diabetic groups were found to be smaller than fetuses from normal groups (Table 4). Vitamin $\mathrm{C}$ treatment did not affect fetal weight. The placental weight tended to be increased in diabetic groups compared to normal groups. Vitamin $\mathrm{C}$ treatment did not affect placental weight in the normal groups, but $4 \%$ vitamin $\mathrm{C}$ supplementation tended to reduce the increase of placental weight in the diabetic group (Table 4).

Organ weights. The fetal organ weight per body weight did not differ between morphologically normal and malformed fetuses, therefore, the data were combined (Table 5). The relative weight of fetal liver did not differ between the N and MD groups, whereas the fetal brain was slightly smaller in the MD group compared to the $\mathrm{N}$ group. Vitamin $\mathrm{C}$ treatment tended to increase these organ weights in the MDC group. In marked contrast, the relative weight of the fetal heart was increased in the diabetic groups compared to the normal groups and vitamin $\mathrm{C}$ treatment did not normalize this difference (Table 5). 


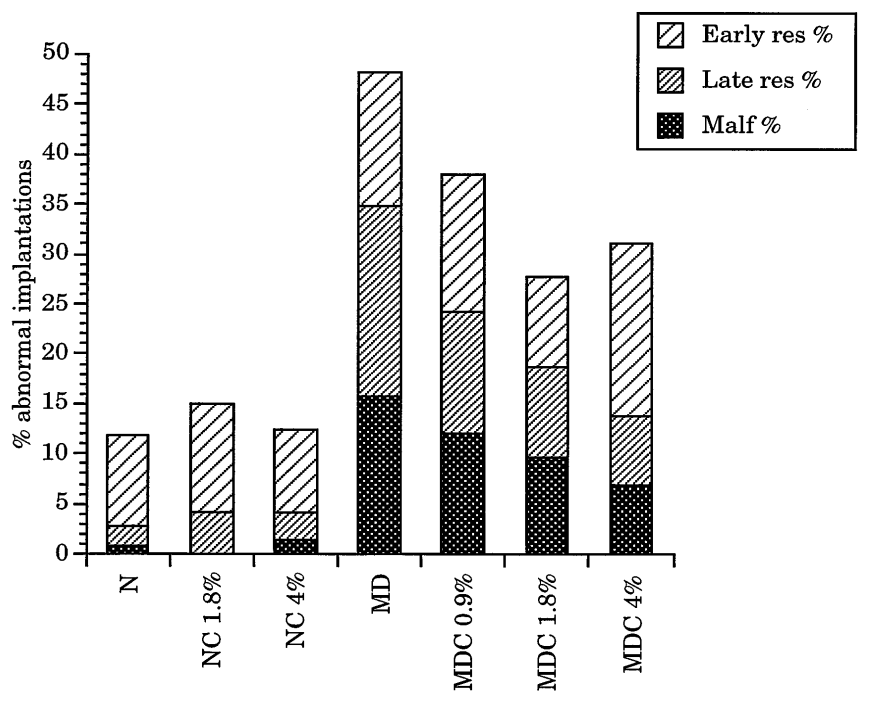

Fig. 2. Outcome of pregnancy on gestational day 20 in the different experimental groups. The numbers of early resorptions, late resorptions, and malformations are expressed in percent of the total number of implantations in each group. Normal and diabetic rats ( $\mathrm{N}$ and $\mathrm{MD}$ ) supplemented with $0.9,1.8$ or $4 \%$ of ascorbate in the diet (MDC $0.9 \%$ or NC $1.8 \%$ and MDC $1.8 \%$ or NC $4 \%$ and MDC $4 \%$, respectively)

Biochemical analysis. We were unable to detect any biochemical difference with regard to concentration of vitamin $\mathrm{C}$, vitamin $\mathrm{E}$, or TBARS between malformed and non-malformed fetuses within each group, which allowed the data on the fetal outcome to be combined without regard to morphology of the fetus. The biochemical estimation in tissues of untreated rats ( $\mathrm{N}$ and $\mathrm{MD}$ groups) and their offspring revealed the lowest ascorbic acid concentrations in placenta and the highest in fetal brain (Table 6). Maternal and fetal liver had similar ascorbic acid concentration. For $\alpha$-tocopherol, the order of tissue concentration was: maternal liver $>$ placenta $>$ fetal brain $>$ fetal liver, which is opposite that of TBARS in the same tissues (Table 6). Compared to maternal liver, maternal serum had low concentration of ascorbic acid and $\alpha$-tocopherol, but similar concentration of TBARS (Table 6).

In maternal serum, diabetes did not affect ascorbic acid concentration, but increased $\alpha$-tocopherol levels and tended to increase TBARS concentration. Ascorbate treatment of the diabetic rats yielded increased ascorbic acid concentration and decreased TBARS levels in serum (Table 6). In maternal liver, diabetes did not affect any of the measured substances, whereas ascorbate treatment increased ascorbic acid and reduced TBARS concentrations in the MDC $4 \%$ group (Table 6). In the placenta, diabetes did not alter the levels of any of the estimated compounds. In both NC $4 \%$ and MDC $4 \%$ groups ascorbate treatment increased ascorbic acid and $\alpha$ tocopherol levels in the placenta of the diabetic rats
Table 5. Relative organ weight on gestational day 20

\begin{tabular}{lrlll}
\hline & $n$ & $\begin{array}{l}\text { Liver/fetal } \\
\text { weight }(\mathrm{mg} / \mathrm{g})\end{array}$ & $\begin{array}{l}\text { Brain/fetal } \\
\text { weight }(\mathrm{mg} / \mathrm{g})\end{array}$ & $\begin{array}{l}\text { Heart/fetal } \\
\text { weight }(\mathrm{mg} / \mathrm{g})\end{array}$ \\
\hline $\mathrm{N}$ & 10 & $45 \pm 1$ & $78 \pm 1$ & $5.4 \pm 0.2$ \\
$\mathrm{NC} 1.8 \%$ & 4 & $44 \pm 1$ & $71 \pm 3^{\mathrm{a}}$ & $5.5 \pm 0.3$ \\
$\mathrm{NC} \mathrm{4 \%}$ & 7 & $44 \pm 1$ & $78 \pm 12$ & $5.7 \pm 0.2$ \\
MD & 13 & $45 \pm 1$ & $73 \pm 1^{\mathrm{a}}$ & $6.5 \pm 0.2^{\mathrm{c}}$ \\
MDC 0.9\% & 5 & $48 \pm 2$ & $77 \pm 4$ & $6.4 \pm 0.1^{\mathrm{b}}$ \\
MDC 1.8\% & 14 & $50 \pm 1^{\mathrm{b} \text { e }}$ & $73 \pm 2$ & $7.0 \pm 0.3^{\mathrm{c}}$ \\
MDC 4\% & 11 & $48 \pm 1$ & $78 \pm 2^{\mathrm{d}}$ & $6.3 \pm 0.2^{\mathrm{b}}$
\end{tabular}

Normal and diabetic rats with standard diet (N and MD) or with $0.9 \%$ (MDC $0.9 \%$ ), $1.8 \%$ (NC $1.8 \%$ and MDC $1.8 \%$ ) or $4 \%$ (NC $4 \%$ and MDC $4 \%$ ) ascorbate added to the diet. Data are presented as fetal organ weight per fetal body weight, mean \pm SEM. $n=$ number of observations

Statistical analysis with ANOVA: ${ }^{\mathrm{a}} p<0.05$ vs N; ${ }^{\mathrm{b}} p<0.01$ vs $\mathrm{N} ;{ }^{\mathrm{c}} p<0.001 \mathrm{vs} \mathrm{N} ;{ }^{\mathrm{d}} p<0.05$ vs MD; ${ }^{\mathrm{e}} p<0.01$ vs MD

Table 6. Estimation of contents of vitamin C, vitamin E, and TBARS in maternal serum, maternal liver, placenta, fetal brain, fetal liver

\begin{tabular}{|c|c|c|c|c|}
\hline & $n$ & $\begin{array}{l}\text { Ascorbic acid } \\
(\mu \mathrm{g} / \mathrm{ml})\end{array}$ & $\begin{array}{l}\alpha \text {-Tocopherol } \\
(\mu \mathrm{g} / \mathrm{ml})\end{array}$ & $\begin{array}{l}\text { TBARS } \\
(\mathrm{nmol} / \mathrm{ml})\end{array}$ \\
\hline \multicolumn{5}{|c|}{ Maternal serum } \\
\hline $\mathrm{N}$ & 10 & $14 \pm 5$ & $3 \pm 1$ & $10 \pm 1$ \\
\hline $\mathrm{NC} 4 \%$ & 6 & $17 \pm 2$ & $6 \pm 1$ & $7 \pm 1$ \\
\hline MD & 12 & $19 \pm 7$ & $9 \pm 2^{\mathrm{a}}$ & $15 \pm 2$ \\
\hline MDC $4 \%$ & 10 & $38 \pm 4^{\mathrm{cd}}$ & $11 \pm 2^{\mathrm{b}}$ & $8 \pm 2^{\mathrm{d}}$ \\
\hline \multicolumn{5}{|c|}{ Maternal liver } \\
\hline $\mathrm{N}$ & 10 & $190 \pm 14$ & $83 \pm 10$ & $12 \pm 0.3$ \\
\hline NC $4 \%$ & 6 & $463 \pm 24^{\mathrm{c}}$ & $95 \pm 7$ & $11 \pm 0.3$ \\
\hline $\mathrm{MD}$ & 12 & $180 \pm 28$ & $87 \pm 12$ & $12 \pm 0.9$ \\
\hline MDC $4 \%$ & 10 & $468 \pm 49^{\mathrm{cf}}$ & $96 \pm 8$ & $10 \pm 0.3^{\mathrm{a}}$ \\
\hline \multicolumn{5}{|l|}{ Placenta } \\
\hline $\mathrm{N}$ & 10 & $46 \pm 5$ & $9 \pm 1$ & $20 \pm 2$ \\
\hline NC $4 \%$ & 5 & $151 \pm 13^{\mathrm{c}}$ & $14 \pm 1$ & $20 \pm 1$ \\
\hline MD & 12 & $50 \pm 11$ & $9 \pm 1$ & $19 \pm 3$ \\
\hline MDC $4 \%$ & 10 & $149 \pm 11^{\mathrm{cf}}$ & $16 \pm 3^{\mathrm{be}}$ & $20 \pm 2$ \\
\hline \multicolumn{5}{|l|}{ Fetal brain } \\
\hline $\mathrm{N}$ & 10 & $605 \pm 20$ & $2 \pm 0.5$ & $54 \pm 3$ \\
\hline NC $4 \%$ & 6 & $561 \pm 31$ & $3 \pm 0.7$ & $50 \pm 5$ \\
\hline $\mathrm{MD}$ & 11 & $580 \pm 14$ & $3 \pm 0.4^{\mathrm{a}}$ & $66 \pm 3^{\mathrm{b}}$ \\
\hline MDC $4 \%$ & 11 & $629 \pm 31$ & $3 \pm 0.4$ & $63 \pm 3$ \\
\hline \multicolumn{5}{|l|}{ Fetal liver } \\
\hline $\mathrm{N}$ & 10 & $192 \pm 9$ & $0.7 \pm 0.2$ & $68 \pm 5$ \\
\hline NC $4 \%$ & 6 & $238 \pm 25^{b}$ & $0.7 \pm 0.3$ & $80 \pm 12$ \\
\hline MD & 10 & $163 \pm 18$ & $0.9 \pm 0.3$ & $411 \pm 27^{c}$ \\
\hline MDC $4 \%$ & 11 & $279 \pm 18^{\mathrm{cf}}$ & $0.6 \pm 0.1$ & $354 \pm 27^{c}$ \\
\hline
\end{tabular}

Normal and diabetic rats with standard diet ( $\mathrm{N}$ and $\mathrm{MD}$ ) or with $4 \%$ ascorbate (NC $4 \%$ and MDC $4 \%$ ) added to the diet. Data are presented as mean $\pm \operatorname{SEM}(n)$.

Statistical analysis with ANOVA: ${ }^{\mathrm{a}} p<0.05$ vs N; ${ }^{\mathrm{b}} p<0.01$ vs $\mathrm{N} ;{ }^{\mathrm{c}} p<0.001$ vs $\mathrm{N} ;{ }^{\mathrm{d}} p<0.05$ vs $\mathrm{MD} ;{ }^{\mathrm{e}} p<0.01$ vs $\mathrm{MD}$; ${ }^{\mathrm{f}} p<0.001$ vs MD

(tendency for $\alpha$-tocopherol in NC $4 \%$ ), but did not affect TBARS concentration (Table 6). In fetal brain, maternal diabetes increased $\alpha$-tocopherol and TBARS levels, whereas ascorbate treatment of the mother did not change any of the studied parameters, 
not even ascorbic acid concentrations (Table 6). In fetal liver we found extremely low $\alpha$-tocopherol levels (less than $1 \%$ of the concentration in maternal liver). No change in ascorbic acid or $\alpha$-tocopherol levels was caused by diabetes, but a pronounced increase in TBARS concentration was detected in the MD offspring. Ascorbate treatment increased ascorbic acid concentration, did not affect $\alpha$-tocopherol concentration, but tended to decrease the elevated TBARS levels in the offspring of diabetic rats (Table 6).

\section{Discussion}

The current report shows that vitamin $\mathrm{C}$ treatment of pregnant streptozotocin diabetic rats has the potential to prevent congenital malformations as well as resorptions occurring in the later part of gestation. The rate of malformations in the diabetic group given $4 \%$ ascorbate in the present study $(8.1 \%)$ is comparable to the rates we previously demonstrated in diabetic rats supplemented with $2 \%$ vitamin $\mathrm{E}$ (5.5\% malformations) or $1 \%$ BHT (2.3\% malformations) $[9,14]$. The doses of vitamin E and BHT are of similar molar concentration, whereas the ascorbate molar dose is approximately four times that of vitamin E and BHT. Thus, it appears that the water soluble antioxidant requires higher doses in order to have a similar effect as the previously tested lipid soluble antioxidants. Assuming that these three antioxidants have the same antioxidative capacity per molecule, the results may suggest that the oxidative process damaging the embryogenesis is mainly confined to the lipid compartment of the cell.

The ascorbate treatment diminished the malformation rate, but also decreased the occurrence of larger resorptions. The latter represents implanted conceptii which died in the later part of pregnancy, presumably due to severe lethal malformations. This notion is supported by findings of malformations in early pregnancy but only resorptions at term in offspring exposed to excess mannose in utero [54]. Assuming that a large proportion of these are due to disturbances in the development of the heart - which is suggested by the persistent cardiac hypertrophy in fetuses of diabetic rats found in this and other studies [9, $55,56]$, as well as by the increased cardiac malformation rate in human diabetic pregnancy [57] - we can suggest a unifying concept for the diabetic dysmorphogenesis by identifying the neural crest cell population as a specific vulnerable cell population. A large proportion of the diabetes-induced viable malformations in this study are likely to be of neural crest origin (micrognathia, and some other facial anomalies), and the late resorptions may represent other, more severe, neural crest cell defects, leading to hampered development of the great vessels and the fetal heart [58]. The effect of the anti-teratogenic treatment would be to block oxidative damage in this cell population. Indeed, this notion is supported by earlier results in vitro, where antioxidant treatment ( $\mathrm{N}$-acetylcysteine) diminished the disrupting effect of high glucose on embryonic neural crest cell development [59].

On the other hand, the small early resorptions are likely to be the result of other aetiologic processes than the late resorptions, since they are only marginally increased in frequency, if at all, by the maternal diabetic state, and they remain unaffected by the ascorbate treatment. In this study, the small resorptions seem to represent a strain-related defect in early embryonic development [60].

The measurement of maternal and fetal anti-oxidative status at term rather than during organogenesis when the dysmorphogenesis is likely to be induced $[56,61,62]$ was dictated by the necessity to recognize the malformations, which in the majority of cases is possible only towards the end of gestation. This applies to micrognathia and other gross malformations. Also, we were interested in studying the effects of the ascorbate treatment, and to find out if a putative imbalance of fetal and maternal antioxidative parameters during early pregnancy would have a discernible correlation in the late gestation. Finding such a fetal or maternal parameter (e.g. in maternal serum) could be of clinical importance, since a large proportion of human malformations present themselves for the first time at birth or in late pregnancy, when there is no possibility of acquiring a sample from the organogenetic period.

The biochemical changes estimated in the different maternal and fetal compartments/organs displayed marked variations, both with regard to diabetes and ascorbate treatment. Thus, the maternal diabetic state did not cause decrease of ascorbate levels, as has been described by other authors [20-23]. Another, somewhat paradoxical, effect of the diabetic state was the slight increase in $\alpha$-tocopherol concentration in maternal serum and fetal brain tissue. These results have been encountered previously in studies of vitamin $\mathrm{E}$ administration to pregnant diabetic rats [9, 15], and should be related to the high lipid concentration of the maternal diabetic serum, as well as in the fetal brain [63], thereby allowing a large amount of $\alpha$-tocopherol to be dissolved in the particular compartments. A compensatory reaction to a diabetes-induced state of oxidative stress, as revealed by the increased TBARS levels in maternal serum and fetal tissue, may also have contributed to the accumulation of $\alpha$-tocopherol in maternal serum and fetal brain.

If the measurements of $\alpha$-tocopherol did not always display an expected pattern, the effect of ascorbate treatment was more predictable. Thus, in almost all tissues we found increased ascorbate levels after administration of the antioxidant to the mother, irrespective if she was diabetic or not. In the placenta, there was evidence of an interaction between the 
antioxidants, since the ascorbate-treated animals showed increased $\alpha$-tocopherol concentration. Lastly, the TBARS concentration was decreased in maternal serum, and tended to be in fetal liver, by ascorbate administration. The results support the notion that ascorbate is readily transported to the conceptus, taken up by the embryonic and fetal tissues, and thereby exerts an antioxidative (and developmentally beneficial) effect in the offspring.

It is evident that diabetes can cause ROS-induced damage in embryonic and fetal tissue [9, 64], and that antioxidants can prevent this damage [9]. The presence of excess radicals has been indicated in vitro in embryonic tissue exposed to high glucose concentrations $[7,8]$. The suggested source for the ROS has been the embryonic mitochondria $[8,65]$, and the effect of the antioxidative agents would be to block the oxidative damage caused. Recently, however, another compound, the reactive oxo-aldehyde 3-deoxyglucosone (3-DG), a strong glycating agent [66], was implicated as a bridging teratogen in hyperglycemia-induced dysmorphogenesis in vitro [67]. This compound is much more reactive than glucose, and able to modify proteins to form AGE-like compounds, which may have profound effects on embryogenesis, unless enough compensatory forces, such as sufficient antioxidative capacity, are present in the embryo. Since the teratogenic effect of 3-DG can be diminished by antioxidants in vitro [67], it is possible that vitamin $\mathrm{C}$ may have exerted some of its effects by counteracting the glycating action of 3-DG, an issue which is currently under investigation.

We found no signs of toxicity with the doses used in the present study, thereby providing support for the feasibility of an anti-teratogenic antioxidant therapy in diabetic pregnancy. If antioxidative treatment with ascorbate will become a clinical entity in the future, the potential prooxidative activity of vitamin $\mathrm{C}$ has to be considered carefully. In the presence of free metals, ascorbic acid can induce radical damage, both in vitro [40] and in vivo in patients with idiopathic haemochromatosis and iron overload [41]. Since free metals are essential for the prooxidative effect, the question arises whether there are sufficient amounts of unbound metals in diabetic individuals to induce autooxidation of ascorbic acid. Glycation of proteins occurs in diabetes, and the binding capacity of transferrin to iron is reduced when this transport protein is glycated [68]. On the other hand, the relevance of glycation in vivo has been questioned [69]. To our knowledge, there are at present no reports showing a prooxidative effect of ascorbic acid in vivo in diabetes (without haemochromatosis). Due to the potential use of ascorbic acid in future prophylactic therapies, these questions need to be further addressed.

In conclusion, we have shown that vitamin $\mathrm{C}$ supplementation to the diet exerts antioxidative effects in pregnant diabetic rats and restores fetal development, i. e. decreases the occurrence of late resorptions and malformations in the litters. Furthermore, the data support that the mechanisms causing early and late resorptions are different. Excess ROS apparently contribute to the aetiology of diabetic complications in pregnancy, and this finding may indicate a direction for future preventive treatments.

Acknowledgements. The authors wish to express their gratitude to Lisbeth Sagulin for excellent technical assistance. The study was supported by The Swedish Diabetes Association, The Juvenile Diabetes Foundation International, The Novo Nordisk Foundation, The Ernfors Family Fund, The Swedish Society for Medical Research, and The Swedish Medical Research Council (Grant No.12X-7475, 12X-109).

\section{References}

1. Kucera J (1971) Rate and type of congenital anomalies among offspring of diabetic women. J Reprod Med 7: 6170

2. Hanson U, Persson B, Thunell S (1990) Relationship between haemoglobin $\mathrm{A}_{1 \mathrm{c}}$ in early type 1 (insulin-dependent) diabetic pregnancy and the occurrence of spontaneous abortion and fetal malformation in Sweden. Diabetologia 33: $100-104$

3. Kitzmiller JL, Gavin LA, Gin GD, Jovanovic-Peterson L, Main EK, Zigrang WD (1991) Preconception care of diabetes. Glycemic control prevents congenital anomalies. JAMA 265: 731-736

4. Rosenn B, Miodovnik M, Combs CA, Khoury J, Siddiqi TA (1994) Glycemic thresholds for spontaneous abortions and congenital malformations in insulin-dependent diabetes mellitus. Obstet Gynecol 84: 515-520

5. Styrud J, Thunberg L, Nybacka O, Eriksson UJ (1995) Correlations between maternal metabolism and deranged development in the offspring of normal and diabetic rats. Pediatr Res 37: 343-353

6. Eriksson UJ, Borg LAH, Forsberg H, Simán CM, Suzuki N, Yang X (1996) Can fetal loss be prevented? The biochemical basis of diabetic embryopathy. Diab Rev 4: 49-69

7. Trocino RA, Akazawa S, Ishibashi M et al (1995) Significance of glutathione depletion and oxidative stress in early embryogenesis in glucose-induced rat embryo culture. Diabetes 44: 992-998

8. Yang X, Borg LAH, Eriksson UJ (1997) Altered metabolism and superoxide generation in neural tissue of rat embryos exposed to high glucose. Am J Physiol 272: E 173E 180

9. Simán CM, Eriksson UJ (1997) Vitamin E decreases the occurrence of malformations in the offspring of diabetic rats. Diabetes 46: 1054-1061

10. Eriksson UJ, Borg LAH (1991) Protection by free oxygen radical scavenging enzymes against glucose-induced embryonic malformations in vitro. Diabetologia 34: 325-331

11. Eriksson UJ, Borg LAH (1993) Diabetes and embryonic malformations. Role of substrate-induced free-oxygen radical production for dysmorphogenesis in cultured rat embryos. Diabetes 42: 411-419

12. Hagay ZJ, Weiss Y, Zusman I et al (1995) Prevention of diabetes-associated embryopathy by overexpression of the free radical scavenger copper zinc superoxide dismutase in transgenic mouse embryos. Am J Obstet Gynecol 173: 1036-1041 
13. Viana M, Herrera E, Bonet B (1996) Teratogenic effects of diabetes mellitus in the rat. Prevention with vitamin E. Diabetologia 39: 1041-1046

14. Eriksson UJ, Simán CM (1996) Pregnant diabetic rats fed the antioxidant butylated hydroxytoluene show decreased occurrence of malformations in the offspring. Diabetes 45: 1497-1502

15. Sivan E, Reece EA, Wu YK, Homko CJ, Polansky M, Borenstein M (1996) Dietary vitamin E prophylaxis and diabetic embryopathy: morphologic and biochemical analysis. Am J Obstet Gynecol 175: 793-799

16. Wentzel P, Thunberg L, Eriksson UJ (1997) Teratogenic effect of diabetic serum is prevented by supplementation of superoxide dismutase and $\mathrm{N}$-acetylcysteine in rat embryo culture. Diabetologia 40: 7-14

17. Loeken MR (1997) Vitamin E may exacerbate the embryopathic effects of diabetic pregnancy. Diabetes 46 [Suppl 1]: 259 A (Abstract)

18. Sakamaki H, Akazawa S, Ishibashi M et al (1997) Diabetes-induced embryopathy and glutathione-dependent antioxidant system. Diabetes 46 [Suppl 1]: 88 A (Abstract)

19. Potashnik Y, Ayalon N, Khamaisi M, Wiznitzer A, Bashan N (1997) Lipoic acid treatment decreases neural tube defects in fetuses of diabetic rats. Diabetologia 40 [Suppl 1]: A 585 (Abstract)

20. Som S, Basu S, Mukherjee D et al (1981) Ascorbic acid metabolism in diabetes mellitus. Metabolism 30: 572-577

21. Yew MS (1983) Effect of streptozotocin diabetes on tissue ascorbic acid and dehydroascorbic acid. Horm Metabol Res 15: 158

22. Chen MS, Hutchinson ML, Pecoraro RE, Lee WY, Labbe RF (1983) Hyperglycemia-induced intracellular depletion of ascorbic acid in human mononuclear leukocytes. Diabetes 32: 1078-1081

23. McLennan S, Yue DK, Fisher E et al (1988) Deficiency of ascorbic acid in experimental diabetes. Relationship with collagen and polyol pathway abnormalities. Diabetes 37: 359-361

24. Bendich A, Machlin LJ, Scandurra O, Burton GW, Wayner DDM (1986) The antioxidant role of vitamin C. Adv Free Rad Biol Med 2: 419-444

25. Niki E (1991) Vitamin C as an antioxidant. World Rev Nutr Diet 64: 1-30

26. Fisher E, McLennan SV, Tada H, Heffernan S, Yue DK, Turtle JR (1991) Interaction of ascorbic acid and glucose on production of collagen and proteoglycan by fibroblasts. Diabetes 40: 371-376

27. Harwood HJ, Greene YJ, Stacpoole PW (1986) Inhibition of human leukocyte 3-hydroxy-3-methylglutaryl coenzyme A reductase activity by ascorbic acid. An effect mediated by the free radical monodehydroascorbate. J Biol Chem 261: 7127-7135

28. Ginter E (1989) Ascorbic acid in cholesterol metabolism and in detoxification of xenobiotic substances: problem of optimum vitamin C intake. Nutrition 5: 369-374

29. Siegenberg D, Baynes RD, Bothwell TH et al (1991) Ascorbic acid prevents the dose-dependent inhibitory effects of polyphenols and phytates on nonheme-iron absorption. Am J Clin Nutr 53: 537-541

30. Nishikimi M, Yagi K (1991) Molecular basis for the deficiency in humans of gulonolactone oxidase, a key enzyme for ascorbic acid biosynthesis. Am J Clin Nutr 54: 1203 S-1208 S

31. Mooradian AD (1987) Effect of ascorbate and dehydroascorbate on tissue uptake of glucose. Diabetes 36: 1001-1004

32. Vera JC, Rivas CI, Fischbarg J, Golde DW (1993) Mammalian facilitative hexose transporters mediate the transport of dehydroascorbic acid. Nature 364: 79-82
33. Goldenberg H, Schweinzer E (1994) Transport of vitamin $\mathrm{C}$ in animal and human cells. J Bioenerg Biomembr 26: $359-367$

34. Norkus EP, Bassi JA, Rosso P (1982) Maternal hyperglycemia and its effect on the placental transport of ascorbic acid. Pediatr Res 16: 746-750

35. Ingermann RL, Stankova L, Bigley RH (1986) Role of monosaccharide transporter in vitamin $\mathrm{C}$ uptake by placental membrane vesicles. Am J Physiol 250: C 637-C 641

36. Beyer RE (1994) The role of ascorbate in antioxidant protection of biomembranes: interaction with vitamin $\mathrm{E}$ and Coenzyme Q. J Bioenerg Biomembr 26: 349-358

37. Packer JE, Slater TF, Willson RL (1979) Direct observation of a free radical interaction between vitamin $\mathrm{E}$ and vitamin C. Nature 278: 737-738

38. Frei B, England L, Ames BN (1989) Ascorbate is an outstanding antioxidant in human blood plasma. Proc Natl Acad Sci USA 86: 6377-6381

39. Frei B, Stocker R, England L, Ames BN (1990) Ascorbate: the most effective antioxidant in human blood plasma. Adv Exp Med Biol 264: 155-163

40. Gutteridge JM, Halliwell B (1989) Iron toxicity and oxygen radicals. Baillieres Clin Haematol 2: 195-256

41. Halliwell B (1996) Oxidative stress, nutrition and health. Experimental strategies for optimization of nutritional antioxidant intake in humans. Free Rad Res 25: 57-74

42. Minetti M, Forte T, Soriani M, Quaresima V, Menditto A, Ferrari M (1992) Iron-induced ascorbate oxidation in plasma as monitored by ascorbate free radical formation. No spin-trapping evidence for the hydroxyl radical in ironoverloaded plasma. Biochem J 282: 459-465

43. Sevanian A, Davies KJA, Hochstein P (1991) Serum urate as an antioxidant for ascorbic acid. Am J Clin Nutr 54: 1129 S-1134 S

44. Cox BD, Butterfield WJH (1975) Vitamin C supplements and diabetic cutaneous capillary fragility. Br Med J 3: 205

45. Kilic F, Mitton K, Dzialoszynski T, Sanford SE, Trevithick JR (1994) Modelling cortical cataractogenesis 14: Reduction in lens damage in diabetic rats by a dietary regimen combining vitamins $\mathrm{C}$ and $\mathrm{E}$ and beta-carotene. Dev Ophthalmol 26: 63-71

46. Vinson J, Hsu C, Possanza C et al (1994) Lipid peroxidation and diabetic complications: effect of antioxidant vitamin $\mathrm{C}$ and E. Adv Exp Med Biol 366: 430-432

47. Cameron NE, Cotter MA (1996) Interaction between oxidative stress and gamma-linolenic acid in impaired neurovascular function of diabetic rats. Am J Physiol 39: $1047-1054$

48. Eriksson UJ (1988) Importance of genetic predisposition and maternal environment for the occurrence of congenital malformations in offspring of diabetic rats. Teratology 37: 365-374

49. Eriksson UJ, Dahlström E, Larsson KS, Hellerström C (1982) Increased incidence of congenital malformations in the offspring of diabetic rats and their prevention by maternal insulin therapy. Diabetes 31: 1-6

50. Jagota SK, Dani HM (1982) A new colorimetric technique for the estimation of vitamin $\mathrm{C}$ using Folin phenol reagent. Anal Biochem 127: 178-182

51. Mihara M, Uchiyama M, Fukuzawa K (1980) Thiobarbituric acid value on fresh homogenate of rat as a parameter of lipid peroxidation in aging, CC14 intoxication, and vitamin E deficiency. Biochem Med 23: 302-311

52. Winer BJ (1971) Statistical principles in experimental design. McGraw-Hill New York

53. Ostle B (1963) Statistics in research. 2nd ed Iowa State University Ames, Iowa 
54. Buchanan TA, Freinkel N (1988) Fuel-mediated teratogenesis: symmetric growth retardation in the rat fetus at term after a circumscribed exposure to D-mannose during organogenesis. Am J Obstet Gynecol 158: 663-669

55. Eriksson UJ, Styrud J, Eriksson RSM (1989) Diabetes in pregnancy: genetic and temporal relationships of maldevelopment in the offspring of diabetic rats. In: Sutherland HW, Stowers JM, Pearson DWM (eds) 4 th International colloquium on carbohydrate metabolism in pregnancy and the newborn. Springer-Verlag, Berlin Heidelberg, pp 51-63

56. Eriksson UJ, Bone AJ, Turnbull DM, Baird JD (1989) Timed interruption of insulin therapy in diabetic BB/E rat pregnancy: effect on maternal metabolism and fetal outcome. Acta Endocrinol 120: 800-810

57. Ferencz C, Rubin JD, McCarter RJ, Clark EB (1990) Maternal diabetes and cardiovascular malformations: predominance of double outlet right ventricle and truncus arteriosus. Teratology 41: 319-326

58. Noden DM, Poelmann RE, Gittenberger-de Groot AC (1995) Cell origins and tissue boundaries during outflow tract development. Trends Cardiovasc Med 5: 69-75

59. Suzuki N, Svensson K, Eriksson UJ (1996) High glucose concentration inhibits migration of rat cranial neural crest cells in vitro. Diabetologia 39: 401-411

60. Muzikova E, Clark DA (1995) Is spontaneous resorption in the DBA/2-mated CBA/J mouse due to a defect in "seed" or in "soil"? Am J Reprod Immunol 33: 81-85

61. Mills JL, Baker L, Goldman AS (1979) Malformations in infants of diabetic mothers occur before the seventh gestational week. Implications for treatment. Diabetes 28: 292 293
62. Eriksson RSM, Thunberg L, Eriksson UJ (1989) Effects of interrupted insulin treatment on fetal outcome of pregnant diabetic rats. Diabetes 38: 764-772

63. Kokoglu E, Ulakoglu E (1991) The transport of vitamin E in plasma and its correlation to plasma lipoproteins in non-insulin-dependent diabetes mellitus. Diab Res Clin Pract 14: 175-181

64. Lee A, Reis D, Eriksson UJ (1997) Embryonic dysmorphogenesis correlates with DNA mutation rate in diabetic rat pregnancy. Diabetes 46 [Suppl 1]: 88 A (Abstract)

65. Eriksson UJ, Borg LAH, Hagay Z, Groner Y (1993) Increased superoxide dismutase (SOD) activity in embryos of transgenic mice protects from the teratogenic effects of a diabetic environment. Diabetes 42 [Suppl 1]: 85 A (Abstract)

66. Thornalley PJ (1995) Advances in glyoxalase research. Glyoxalase expression in malignancy, anti-proliferative effects of methylglyoxal, glyoxalase I inhibitor diesters and S-D-lactoylglutathione, and methylglyoxal-modified protein binding and endocytosis by the advanced glycation endproduct receptor. Crit Rev Oncol Hematol 20: 99-128

67. Eriksson UJ, Wentzel P, Minhas HS, Thornalley PJ (1997) High 3-deoxyglucosone (3-DG) concentration in malformed rat embryos in vitro. Diabetologia 40 [Suppl 1]: A 233 (Abstract)

68. Fujimoto S, Kawakami N, Ohara A (1995) Nonenzymatic glycation of transferrin: decrease of iron-binding capacity and increase of oxygen radical production. Biol Pharm Bull 18: 396-400

69. Wolff SP, Jiang ZY, Hunt JV (1991) Protein glycation and oxidative stress in diabetes mellitus and ageing. Free Radic Biol Med 10: 339-352 